\title{
PSYCHOMOTOR AND COGNITIVE SKILLS THAT MAKE A DIFFERENCE IN TENNIS PLAYERS AT NATIONAL LEVEL
}

\author{
Radu PREDOIU' ${ }^{1}$, Răzvan ITU², Costel CURCĂ², Ștefan TÜDÖS', \\ Rareș STĂNESCU ${ }^{1}$, Alexandra PREDOIU ${ }^{1 *}$, Lucian Mihai CIUNTEA ${ }^{3}$ \\ ${ }^{1}$ National University of Physical Education and Sport, Faculty of Physical Education and Sport, \\ Bucharest, Romania \\ ${ }^{2}$ Romanian Tennis Federation, Bucharest, Romania \\ 3 "Vasile Alecsandri” University, Faculty of Movement, Sports and Health Sciences, Bacău, Romania \\ * Corresponding author: alexandra.predoiu@yahoo.com
}

https://doi.org/10.35189/dpeskj.2020.59.4.6

\begin{abstract}
Tennis has become an extremely complex sport, with tennis players needing a team of specialists to maximise their sports performance. Performance tennis has proven that the difference between the players, in the conditions of similar technical-tactical performances, is made by the physical and mental training. Our paper aimed to investigate the subjective reality of junior tennis players in order to optimise their actions and activities by identifying a psychomotor and cognitive model of athletes ranked in the top area nationally. The research involved 75 tennis players - 40 boys and 35 girls aged between 14 and 16 years. The materials used were represented by the PSISELTEVA psychological testing system developed by the RQ Plus Company and calibrated to the Romanian population, which contains: levers, desk with buttons, pedals. The tests belonging to the computerised battery used in the research are: TRS (simple reaction time), TRD (discrimination reaction time), RCMV (intersegmental coordination), TUD (eye-hand coordination), ANALOGIE (analogical transfer), TAC (attention concentration), MT (topographical memory) and RNE (resistance to mental fatigue). Through the Mann-Whitney $(U)$ test, significant differences were identified between the first tennis players in the national ranking and the players placed in the middle or final zone of the ranking, in terms of different psychomotor and cognitive coordinates (investigated in various environmental conditions). The results obtained are useful both for specialists working in the field of tennis (coaches, sports psychologists, physical trainers), athletes (boys and girls) aspiring on the road to great performance, but also for sports clubs.
\end{abstract}

Keywords: tennis, coordination, reaction time, topographical memory, resistance to mental fatigue.

\section{Introduction}

Achieving sports performance can be, both for athletes and for specialists involved in sports, the main motivation for the development of the instructive-training process, which is sometimes very difficult (due to time, energy, and material costs). Psychological training is an essential component completing an athlete's training through its psychomotor, intellectual or cognitive, affective, volitional and personality aspects, along with the technical, tactical, and physical training, in addition to nutrition and recovery. We can also add to the very important aspects that facilitate the achievement of sports success the component related to avoiding the consumption of substances (alcohol and psychoactive substances), since the dysfunctional patterns of behaviour (including at high risk) that are characteristic in such situations are very well known (Piotrowski et al., 2020). Last but not least, we emphasise the importance of modelling the competition in training. In order to obtain the performance, the athlete enters a training process which, if it is characterised by routine, monotonous actions, without perceived stake, carried out in stable environmental conditions, with known people 
and functional schemes, develops skills which are inoperative in competition. The paradox of sports training consists precisely in the antagonism of routine activities, monotonous, without stakes, with the desire to achieve a performance in conditions of high social and material stakes, as a unique and unrepeatable event (Tüdös, 2000).

The psychomotor and cognitive skills addressed in this paper refer to: simple reaction time, discrimination reaction time and reaction time to complex stimuli, hand-eye coordination and intersegmental coordination (manifested in different conditions), focused attention, topographical memory, analogical transfer ability (accuracy and speedy responses), alertness and mental toughness.

In the area of psychomotricity, more precisely in terms of coordination, researchers address for example the oculo-manual coordination (Kaiser et al., 2009), emphasising the importance of this type of coordination, which is a predictor of activities of fineness. Other specialists focus their studies on intersegmental coordination during walking and running (Lamoth et al., 2009), or on the effects of fatigue, referring to changes in different execution indices (Zory et al., 2009). The researchers' attention also focused on the difficulties of training, acquisition, and coordination skills (Castelnau et al., 2007). Coordination is the ability to execute precise, fine, and controlled movements (O'Sullivan et al., 2014). Coordinated movements always involve a pattern of action. We notice (depending on the limbs involved) the hand-eye, foot-eye and intersegmental coordination (Aniţei, 2007). The essence of coordination is the timing and the extent to which the different muscle groups are activated at the right time (Schumway-Cook \& Woollacott, 2012). Coordination is required at a high level in the case of technical executions, in sports in general (Goethel et al., 2019). In tennis, some players use the backhand shot with one hand, while others prefer to use two hands for the backhand. Erman et al. (2013) showed that the backhand performed with two hands is not more effective than the backhand performed with one hand in terms of aiming in tennis and in the case of the performances recorded for the eye-hand coordination.

Reaction time is a variant form of motor responses. In 1865, the physiologist Donders (Kantowitz et al., 2015) spoke about three types of reaction, which he called A, B and C. In the first case we refer to a simple reaction (there is only one stimulus and one response) and it measures the speed of transmission of a nerve impulse. Type B reaction involves several stimuli, and for each stimulus there is a unique response (in our case, the athlete pressing a pedal or a button on the handle, depending on the stimuli appearing on the computer screen). Type B measures the speed of transmission of a nerve impulse and the time required for mental operations to identify the stimulus (identifying the type of stimulus and its position) and select the response (selecting the right movements). When several stimuli are found, and the athlete has to react to one (the rest being ignored) we talk about type $\mathrm{C}$ reaction. This type $\mathrm{C}$ does not require the selection of a certain response (as a mental operation), because only one response is the right one.

The motor reaction time is measured in milliseconds. When it comes to tennis, we can measure reaction time in tasks that involve: discrimination, location, recognition, etc. Reaction time values can be improved by training up to a plateau limit (Aniţei, 2007). It seems that the reaction time at the level of the upper limbs (elite athletes, martial arts practitioners were investigated) is not significantly affected by the different colours of the 
opponents' equipment (Cojocariu et al., 2019). We further highlight how the reaction time changes for men and women, depending on age (Davis et al., 2000).

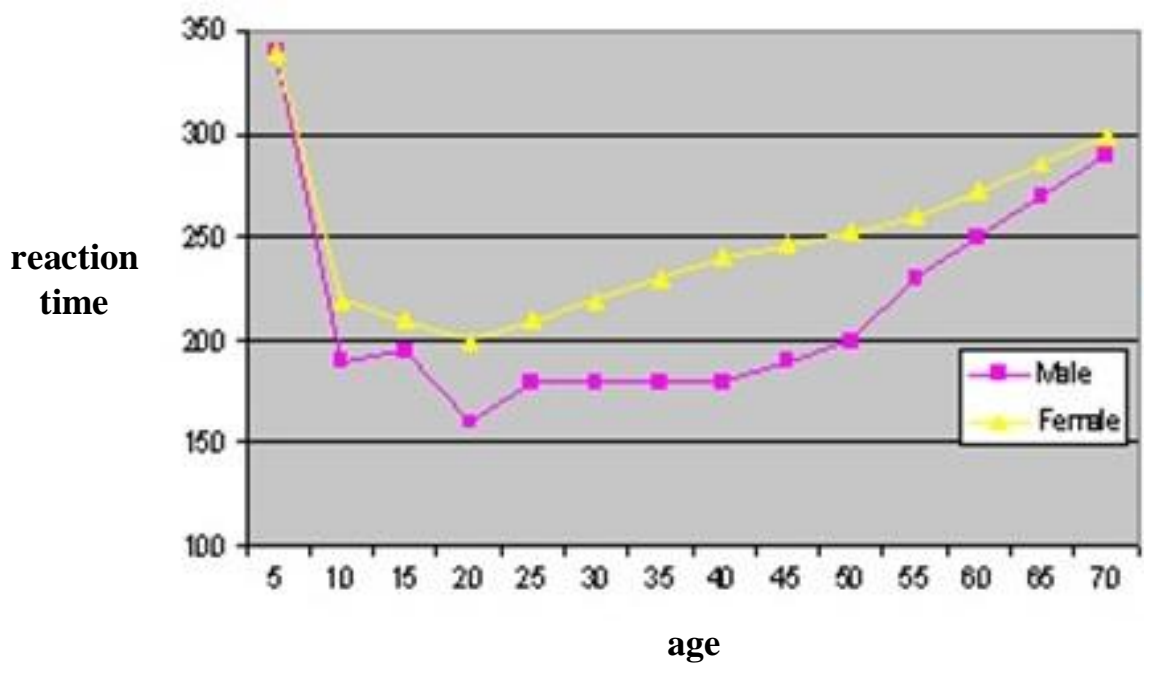

Figure 1. Motor reaction - men and women, depending on age

Reaction time (and vigilance too) can be used to investigate the resistance to mental fatigue of athletes. Since longer periods of physical and mental activity cause errors in technical-tactical executions (Boksem \& Tops, 2008), the development of mental toughness, of resistance to mental fatigue is an achievable goal for specialists. Gould et al. (1999), after having studied tennis coaches, specify the importance that sports performance programmers are rendering to mental abilities, which are considered to be the most difficult to build. Among the most difficult mental skills to teach (according to tennis coaches) are: emotional control, positive management of errors, crisis management, motivation, self-confidence and visualisation (Crespo et al., 2006). Problems also occur in the visualisation stages of tennis players. There are situations in which tennis players may have difficulty creating external images, as the predominant senses are visual and kinaesthetic. Thus, in trying to visualise a technical element, instead of an external image, it is easier for the athlete to use internal images accompanied by sensations related to the actual movement (Stănescu, 2014a). The authors also present the perspective of tennis players. Thus, among the most important mental skills that facilitate success in competition are: concentration, self-confidence, the ability to control anxiety and stress, determination and commitment. With regard to the ability to control perceived stress, Piotrowski (2018) emphasises the importance of training (mental training, in the case of tennis) conducted as soon as one's career begins, in order to better manage health.

Referring to the analogical transfer ability, we mention that effective learning depends on this ability. Transfer is considered an essential component of intelligence (Sternberg, 1977), and it refers to the way in which the knowledge acquired in one context can facilitate the assimilation of new inputs in another context. The transferred knowledge can be declarative or procedural, referring, for example, to execution rules (Chen, 2002). We mention that there are few studies standing out that address the analogical transfer in performance sports. For 
example, Grigore et al. (2016) distinguished a positive correlation between sports performance (expressed by the national ranking at the time of testing) and the response time of junior tennis players in tasks that require this analogical transfer ability (only top athletes participated in the study). Moreover, the ability of nonverbal and verbal analogical transfer is considered an important feature of informal leaders in handball (Predoiu et al., 2017).

Focused attention facilitates the achievement of superior results in competition (Hsieh et al., 2010), including in tennis - it is about focusing attention when tasks are performed at an increased speed (Tüdös et al., 2015). An athlete's ability to keep their attention focused depends on their willingness to self-regulate (Furley et al., 2013). Attention must be trained, taking into account that we are dealing with two types of attention at the level of tennis players, external and internal attention. Internal, as well as external attention has two subcomponents, namely near/close and far/distant. In the case of close internal attention, we refer to the player's thoughts, and distant internal attention is represented by strategy and tactics. The close external attention is related to the opponent and the ball, and distant external attention is related to the referee's decisions or the attitude of the spectators (Stănescu, 2014b).

Topographical memory, an essential cognitive component of human working memory, involves manipulating information about the visual and spatial aspects of the surrounding environment (Pearson et al., 2014). It seems that older people (46-67 years old), but also women have lower performance when it comes to the skills of creating and using mental maps, as compared to younger participants (18-30 years, 31-45 years) (Liu et al., 2011). Topographical memory is important in tennis considering the movements that athletes must make on the field, movements that may or may not increase the chances of an athlete to reach and hit the ball correctly (Predoiu, 2016) - we refer, for example, to the importance moving on the bisector of the angle formed by the place from which the opponent hits the ball and their possibilities of action in the other half of the field.

Generally, in sports, including tennis, it goes without saying that good eye-hand and intersegmental coordination, good reaction time (simple reaction time, discrimination reaction time and reaction time to complex stimuli), a high level of attention, vigilance, good topographical memory and good resistance to mental fatigue are aspects that facilitate the achievement of good sports performance. However, things can be analysed in more detail, more specifically, there are different conditions in which, for example, hand-eye coordination and intersegmental coordination are being manifested. The following are noticed: eye-hand coordination and intersegmental coordination when there are disturbing factors in the environment, (eye-hand and intersegmental) coordination under new perceptual conditions, but also in conditions where there is an increase in the dynamics of situations (we refer to the extent to which an athlete correctly performs the required movements when facing time pressure, when unpredictable stimuli occur in the environment, alternating brightness, or when integrating into a new task).

With regard to cognitive skills, we can ask ourselves, however, what are those dimensions specific to tennis players that have reached the top nationally? To find the answer to this question, it is necessary to have a statistically significant difference between their results (obtained at cognitive level) and the results of other athletes of the same age, who ranked in the middle or last. There are questions that remain unanswered, namely: "What are the 
psychomotor dimensions and the conditions under which they manifest that are specific to the first junior (male and female) tennis players in Romania?" and "What are the cognitive dimensions and conditions under which they manifest themselves (for example, the dynamic of situations increases, there are new perceptual conditions or disturbing factors in the environment) specific to top junior tennis players at national level?" Such aspects are investigated in this paper, knowing that the optimisation of the training process by developing appropriate psychomotor and intellectual coordinates (which make a difference) results in reduced time, energy and even financial costs.

\section{Objectives}

- optimising the actions and activities of tennis players (boys and girls) aged between 14 and 16 years;

- identification of psychomotor and cognitive coordinates specific to junior tennis players with superior results in training and competition (separately for boys and girls) by investigating: simple reaction time, discrimination reaction time and complex reaction time, eye-hand coordination and intersegmental coordination (manifested in different conditions), attention concentration, topographical memory, analogical transfer capacity (accuracy and speedy responses), resistance to mental fatigue and vigilance.

\section{Hypotheses}

H1: Different psychomotor coordinates (simple reaction time, discrimination and complex reaction time, eye-hand and intersegmental coordination) induce significant differences between top tennis players and athletes ranked in the middle or final zone of the national ranking.

H2: The investigation of cognitive dimensions (analogical transfer ability, attention concentration, topographical memory, resistance to mental fatigue and vigilance) reveals significant differences between top tennis players and athletes placed in the middle or final zone of the national ranking.

\section{Methodology}

\section{Participants}

The research involved a total of 75 tennis players - 40 boys and 35 girls aged between 14 and 16 years. There are four groups of tennis players, two made up of male athletes and two consisting of female athletes, as follows:

- 20 top tennis players (boys) ranked among the top 12 players at national level in different years (we mention that some athletes were ranked among the first players in the European ranking under 16); 
- 20 athletes (boys) placed in the middle or in the final zone of the national ranking (between position 50 and 130 in the age category $15-16$ years);

- 16 top tennis players (girls) ranked among the top 10 juniors in Romania in different years - we mention that approximately $32 \%$ of athletes recorded very good performances, also, at European level, being included in the top 10 players in Europe under 16 years;

- 19 athletes (girls) placed in the middle or final part of the national ranking (between position 50 and 130 in the age category 15-16 years).

\section{Instruments/ Devices}

The materials used are represented by the psychological testing system PSISELTEVA, developed by the company RQ Plus, calibrated on the Romanian population, which contains: levers, desk with buttons, pedals (Figure 2).

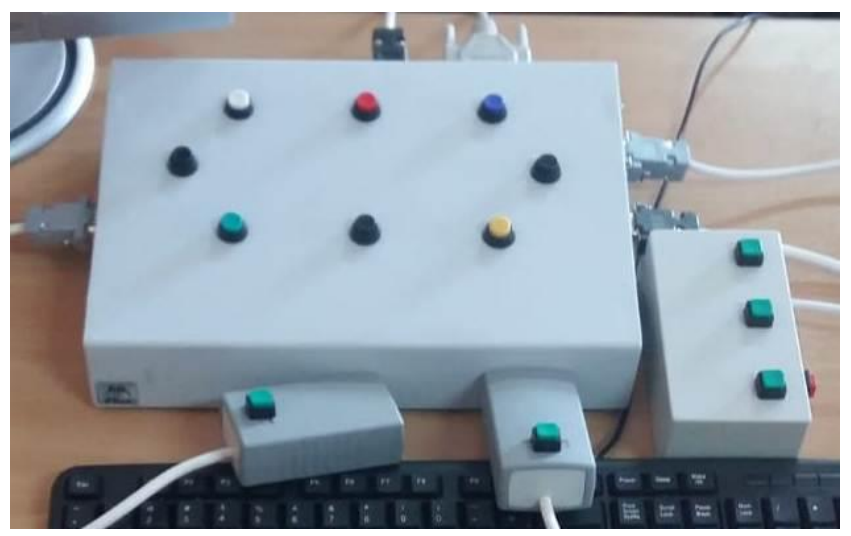

Figure 2. The computerised PSISELTEVA system

The tests belonging to the computerised PSISELTEVA battery used in the research are: TRS (simple reaction time), TRD (discrimination reaction time), RCMV (intersegmental coordination and complex reaction time), TUD (eye-hand coordination), ANALOGIE (verbal analogical transfer), TAC (attention concentration), MT (topographical memory) and RNE (resistance to mental fatigue). For each computerised test, a series of coefficients are generated automatically. The generated coefficients take into account: the existence of disturbing factors (unpredictable appearance of signal-stimuli, distraction, alternation of brightness); time pressure (in the case of computerised tests the dynamics of situations increase, the tasks are running more and more quickly); the ability to adapt to new perceptual conditions (it is only about the beginning area of the tests, when the athlete integrates into a new task). In the case of resistance to mental fatigue, a low score reflects a large number of errors in the case of vigilance and an increased simple reaction time (poor performance) under conditions where the athlete is "bombarded" with monotonous stimuli.

The eight samples/tests used require athletes to react as quickly and correctly as possible (pressing buttons on the handles or pressing the pedals), depending on the specifics of the test and stimuli/images displayed on the computer screen (geometric figures appear in different 
areas of the screen or objects that change colour - aspects that involve the existence of suitable motor reactions, athletes are asked to follow moving targets, to remake previously memorised routes, to identify the appropriate verbal solution in the case of the analogical transfer test, etc). The stimuli appear randomly during the tests (and at different intervals in the case of tests that address the reaction time) and cannot be anticipated by athletes. The use of computer technology ensures the accuracy and the precision of the collected data.

\section{Procedure}

The study was carried out in the last years, in collaboration with the Romanian Tennis Federation. Starting with 2014, the best tennis players in the country (14-16 years old) were investigated from the point of view of different psychomotor and cognitive dimensions, in order to capture both the strong aspects and the weaknesses, for future personal and professional development. Following the testing period, each athlete received, on their e-mail address, both the personal profile and the description of the evaluated dimensions, for future development. In parallel, as sports psychologists (two of the authors of this paper), we have continued the testing activity, investigating junior tennis players who are both in leading positions and in the middle or final zone of the national ranking (between position 50 and 130 in the age category 15-16 years, boys and girls).

Regarding computerised tests, the use of the computer makes the training identical for all athletes (the standard training was read by the athlete before performing each test). At the same time, the ambiguities were discussed before the start of the test. The eight computerised tests were performed by athletes relatively at the same time of day - in the afternoon and in the same order, namely: ANALOGIE, MT, TAC, TRS, TRD, TUD, RCMV and RNE. Participants were at rest, not having previously practicing physical activities - leading to an increase in heart rate (for example, up to 115 beats/minute) and thus an improvement in reaction time (Levitt \& Gutin, 1971). The eight computerised tests took about 90 minutes.

\section{Ex post facto design}

In the case of our research, the results recorded by athletes in the computerised tests investigating the psychomotor and cognitive (intellectual) domain play the role of dependent variables (DVs), and the membership of athletes in one of the two groups of tennis players "top" (placed among the top 10-12 juniors at national level) and "final" (players placed in the middle or final area of the national ranking) plays the role of independent variable. If the difference between the values of the DVs for the two groups is statistically significant, this difference is probably not due to the chance, an important role being played by the independent variable.

\section{Results}

Preliminary data analysis showed that, in the case of the results recorded by junior tennis players, no excessive values were found (which could influence the conclusions of the study). We present the results obtained, separately, in the case of boys and girls. 
Boys

Through the Mann-Whitney (U) test for two independent samples, we checked whether there were statistically significant differences between the top tennis players (placed among the top 12 players in the national ranking) and the tennis players placed in the middle or final zone of the ranking, considering the different psychomotor and cognitive coordinates investigated (which manifests itself in different environmental conditions).

Table 1. U test results for the investigated psychomotor and cognitive coordinates (boys)

\begin{tabular}{|c|c|c|c|}
\hline Junior tennis players & $\mathrm{Z}$ & $\mathrm{p}$ & $\mathrm{r}$ \\
\hline learning ability - in tasks requiring IC & -2.383 & .016 & 0.37 \\
\hline performance coefficient (accuracy/ time) - in tasks requiring IC & -.690 & .525 & 0.11 \\
\hline complex reaction time & -.344 & .740 & 0.05 \\
\hline resistance to disruptive factors - in tasks requiring IC & -2.238 & .027 & 0.35 \\
\hline personal optimum rhythm (accuracy, only in the case of IC) & -.032 & .976 & 0.005 \\
\hline resistance to time pressure - in tasks requiring IC & -2.576 & .009 & 0.40 \\
\hline perceptual inspection of the environment - in tasks requiring IC & -.800 & .566 & 0.12 \\
\hline self-pace (tempo) - the speed of movements in tasks requiring IC & -2.238 & .027 & 0.35 \\
\hline target percentage (at low speed) - E-HC & -.340 & .740 & 0.017 \\
\hline target percentage (at high speed) - E-HC & -.186 & .880 & 0.009 \\
\hline learning ability - in tasks requiring E-HC & -.890 & .413 & 0.14 \\
\hline performance coefficient (accuracy/ time) - in tasks requiring E-HC & -.125 & .928 & 0.006 \\
\hline resistance to disruptive factors - in tasks requiring E-HC & -2.075 & .043 & 0.33 \\
\hline resistance to time pressure - in tasks requiring E-HC & -2.383 & .016 & 0.37 \\
\hline discrimination reaction time & -.031 & .976 & 0.005 \\
\hline simple reaction time & -.617 & .556 & 0.09 \\
\hline analogical transfer capacity - accuracy (number of correct responses) & -.947 & .379 & 0.15 \\
\hline analogical transfer capacity - operability (response speed) & -.840 & .413 & .013 \\
\hline topographical memory coefficient - response accuracy (TM) & -.969 & .347 & 0.15 \\
\hline performance coefficient (accuracy/ time) - in tasks requiring TM & -.593 & .566 & 0.09 \\
\hline time or response speed - in tasks requiring TM & -.527 & .608 & 0.08 \\
\hline correct response speed 1 (low speed) - attention concentration & -.559 & .608 & 0.09 \\
\hline correct response speed 2 (increased speed) - attention concentration & -.062 & .976 & 0.005 \\
\hline learning ability - in tasks requiring $\mathrm{AC}$ & -1.066 & .316 & 0.16 \\
\hline resistance to disruptive factors - in tasks requiring $\mathrm{AC}$ & -.218 & .833 & 0.03 \\
\hline resistance to mental fatigue (in the absence of disturbing factors) & -2.194 & .034 & 0.34 \\
\hline resistance to disruptive factors - in tasks requiring $\mathrm{RMF}$ & -.408 & .695 & 0.06 \\
\hline vigilance & -1.443 & .190 & 0.22 \\
\hline
\end{tabular}

Note: IC: intersegmental coordination; E-HC: eye-hand coordination; TM: topographical memory; AT: attention concentration; RMF: resistance to mental fatigue.

Analysing Table 1 , the significant differences highlighted $(\mathrm{p}<.05)$ between the two groups of tennis players refer to: learning ability, resistance to disruptive factors, resistance to time pressure, speed of movement (all in tasks that require intersegmental coordination), resistance to disruptive factors and resistance to time pressure (in tasks requiring eye-hand coordination) and resistance to mental fatigue. The effect size index (r) highlights a moderate difference, respectively a moderate to strong difference (Predoiu, 2020) - we refer to the dimensions in which statistically significant differences are observed. In other words, the fact that tennis players belong to the top group at national level has a moderate or a moderate to strong effect on the investigated variables.

We mention that, for the obtained results: in the case of fast inspection of the perceptual field and accuracy of movements (intersegmental coordination); in the case of the ratio 
between accuracy and response time (intersegmental coordination and eye-hand coordination); regarding the fast adaptation of movements to new perceptual conditions (we refer to movements that involve eye-hand coordination); regarding the time spent on target (eye-hand coordination test); in the case of simple, discrimination and complex reaction time; in the case of analogical transfer capacity (response accuracy and speed); in the case of topographical memory (response accuracy and speed); in terms of attention (in new perceptual conditions, but also when there are disturbing factors in the environment); in the case of vigilance, but also regarding the resistance to mental fatigue in the presence of disturbing factors in the environment, no statistically significant differences were found between the two groups of athletes - top junior tennis players and tennis players placed in the middle or final zone of the national ranking.

Girls

Using the $\mathrm{U}$ test, we also checked whether there were statistically significant differences between the top tennis players (placed among the top 10 players in the national ranking) and the tennis players placed in the middle or final zone of the ranking, considering the same psychomotor and cognitive coordinates investigated above.

Table 2. Mann-Whitney test results for psychomotor and cognitive coordinates - girls

\begin{tabular}{cccc}
\hline Junior tennis players & $\mathrm{Z}$ & $\mathrm{p}$ & $\mathrm{r}$ \\
\hline learning ability - in tasks requiring IC & -2.185 & .035 & 0.36 \\
complex reaction time & -.988 & .360 & 0.16 \\
performance coefficient (accuracy/ times requiring IC & -1.030 & .315 & 0.17 \\
resistance to disruptive factors - in tasks requiring IC & -.181 & .897 & 0.03 \\
personal optimum rhythm (accuracy, only in the case of IC) & -.046 & .965 & 0.007 \\
resistance to time pressure - in tasks requiring IC & -.415 & .696 & 0.07 \\
perceptual inspection of the environment - in tasks requiring IC & -1.411 & .203 & 0.23 \\
self-pace (tempo) - the speed of movements in tasks requiring IC & -.357 & .762 & 0.06 \\
target percentage (at low speed) - E-HC & -.523 & .640 & 0.08 \\
target percentage (at high speed) - E-HC & -.269 & .829 & 0.04 \\
learning ability - in tasks requiring E-HC & -2.922 & .003 & 0.49 \\
discrimination reaction time & -.358 & .762 & 0.06 \\
simple reaction time & -.537 & .633 & 0.09 \\
performance coefficient (accuracy/ time) - in tasks requiring E-HC & -.179 & .897 & 0.03 \\
resistance to disruptive factors - in tasks requiring E-HC & -2.194 & .034 & 0.37 \\
resistance to time pressure - in tasks requiring E-HC & -.712 & .515 & 0.12 \\
analogical transfer capacity - accuracy (number of correct responses) & -.538 & .633 & 0.09 \\
analogical transfer capacity - operability (response speed) & -1.123 & .274 & 0.19 \\
topographical memory coefficient - response accuracy (TM) & -2.651 & .007 & 0.44 \\
performance coefficient (accuracy/ time) - in tasks requiring TM & -2.446 & .014 & 0.41 \\
time or response speed - in tasks requiring TM & -1.461 & .173 & 0.24 \\
correct response speed 1 (low speed) - attention concentration & -1.303 & .203 & 0.22 \\
correct response speed 2 (increased speed) - attention concentration & -.893 & .408 & 0.15 \\
learning ability - in tasks requiring AC & -.046 & .965 & 0.007 \\
resistance to disruptive factors - in tasks requiring AC & -1.563 & .146 & 0.26 \\
resistance to mental fatigue (in the absence of disturbing factors) & -2.541 & .010 & 0.43 \\
resistance to disruptive factors - in tasks requiring RMF & -.537 & .633 & 0.09 \\
vigilance & -1.096 & .315 & 0.18 \\
\hline
\end{tabular}

Note: IC: intersegmental coordination; E-HC: eye-hand coordination; TM: topographical memory; AT: attention concentration; RMF: resistance to mental fatigue. 
Analysing Table 2 , the significant differences $(\mathrm{p}<.05)$ highlighted between the two groups of tennis players refer to: learning ability (in tasks that require both intersegmental and eye-hand coordination), discrimination reaction time, topographical memory (we refer to the accuracy of responses but also to the relationship between accuracy and the time in which athletes completed the test) and resistance to mental fatigue. In the case of these coordinates, the effect size index (r) shows a moderate to strong intensity, respectively a strong intensity. In other words, the fact that tennis players belong to the top group at national level has a moderate to strong effect on the mentioned variables/coordinates (we emphasise a strong effect on learning ability in task requiring E-HC).

In the case of the results obtained for: fast inspection of the perceptual field; speed and accuracy of movements (intersegmental coordination); the ratio between accuracy and response time (intersegmental and eye-hand coordination); time spent on target (eye-hand coordination test); resistance to disruptive factors and resistance to time pressure (intersegmental and eye-hand coordination); simple and complex reaction time; analogical transfer capacity (accuracy and speed of responses); topographical memory (we refer to the time in which the athletes have finished the test); attention concentration (in new perceptual conditions, but also when there are disturbing factors in the environment); vigilance and for the resistance to mental fatigue in the presence of disturbing factors in the environment, no statistically significant differences were found between the two investigated samples - top junior tennis player and junior tennis player placed in the middle or final area of the national ranking.

\section{Conclusion}

Our work started from the desire to support tennis specialists, athletes, but also their parents on their way filled with obstacles towards great performance. The researched problem is particularly important because in the race for high performance, both coaches, athletes and parents want permanent progress, which is facilitated by adequate psychological training and by knowing optimal training procedures. The existence of a favourable climate at home, when training and in competition add thereto, knowing that the satisfaction felt by a person influences their intention to continue or change the space in which they carry out the activity (adapted after Nikkhah-Farkhani \& Piotrowski, 2020).

The support of the actors involved in the competitive space lies in the achievement of a psychomotor and cognitive model of the junior tennis players (boys and girls) ranked in top positions at national level. We considered that top rankings are: among the top 12 juniors in the country (for boys) and among the top 10 juniors in the national ranking (for girls). Therefore, we wanted to identify the psychomotor and cognitive (intellectual) coordinates, whose development facilitates the obtaining of superior results in competitions.

The design of such a model makes it possible to optimise the behaviour and the training process. The development of skills that make a difference requires that some strategies, techniques, exercises take precedence over others, and among their effects is the reduction of time, energy and even financial costs. 
The following aspects are original contributions made in the field of sports science. Top junior tennis players (boys), as opposed to tennis players of the same age placed in the middle or final zone of national ranking: they coordinate themselves better (it is both about intersegmental coordination and about eye-hand coordination) when facing a problem - we refer to the unpredictable occurrence of signal stimuli, distraction, but also when there is an increase in the dynamics of situations (speed is imposed from the outside); they adapt their movements better to new perceptual conditions (it is about the correctness of the movements that imply intersegmental coordination, performed under conditions that are new for athletes); they perform coordinated movements faster (we refer to the speed of movements that require intersegmental coordination) and they issue, against a background of mental fatigue (in the conditions of the existence of monotonous stimuli in the environment), a greater number of correct responses and a smaller number of erroneous responses that are anticipated, delayed or omitted (they have more appropriate psycho-behavioural reactions under conditions of mental fatigue).

Top junior female tennis players, unlike female tennis players of the same age placed in the middle or final zone of the national ranking: they have better intersegmental coordination, but also a better eye-hand coordination (more precisely, it is about the correctness of the movements that involve intersegmental and eye-hand coordination, performed under conditions that are new for the athletes); they have a significantly better discrimination reaction time - we are talking about the transmission speed of the nerve impulse and about the time required for the mental operation to identify the relevant stimuli in the environment; they issue, under conditions of mental fatigue (when monotonous stimuli are present in the environment), a greater number of correct responses and a smaller number of erroneous, delayed, anticipated or omitted responses. At the same time, they retain routes better, they form visual mental maps more easily (they offer more exact responses, having a better ratio between accuracy and response time in tasks that require topographical memory).

In the same sphere of original contributions is the highlighting of psychomotor and intellectual coordinates whose development does not facilitate (significantly statistically) the achievement of better results in competitions, in other words, they do not facilitate access to the top group at national level. The models presented in a synthetic-integrative form (Figures 3 and 4) make the optimisation of the preparation process possible. Thus, specialists can choose, can focus on appropriate strategies and techniques for the development of priority psychomotor and cognitive (intellectual) qualities, which make a difference in tennis. 


\section{JUNIOR TENNIS PLAYERS - FIRST 12 RANKED ATHLETES (BOYS) AT NATIONAL LEVEL}

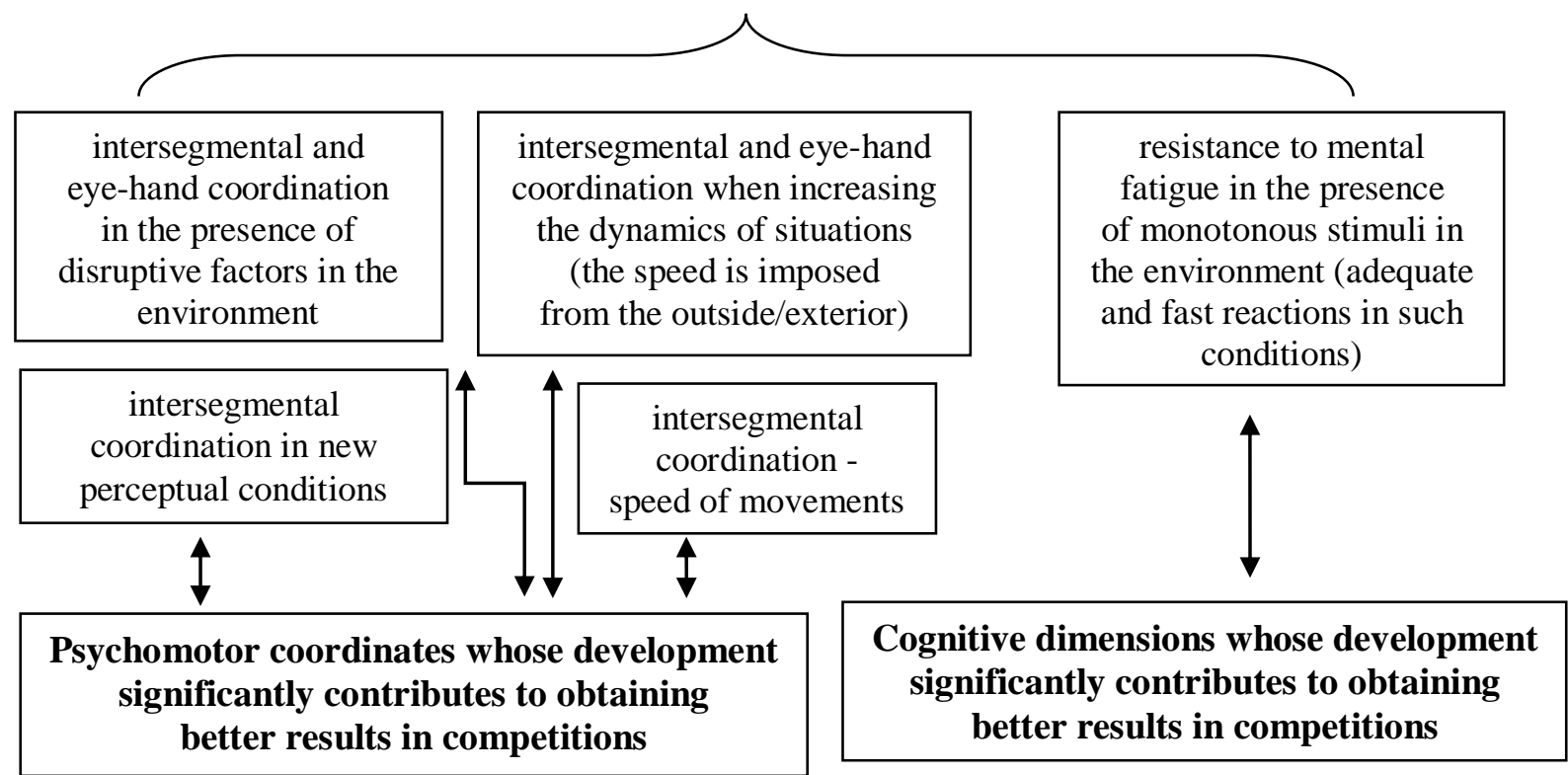

\section{JUNIOR TENNIS PLAYERS - BETWEEN 50 - 130 IN THE NATIONAL RANKING}

Figure 3. Psychomotor and cognitive model of performance junior tennis players (boys)

\section{JUNIOR TENNIS PLAYERS - FIRST 10 RANKED ATHLETES (GIRLS) AT NATIONAL LEVEL}

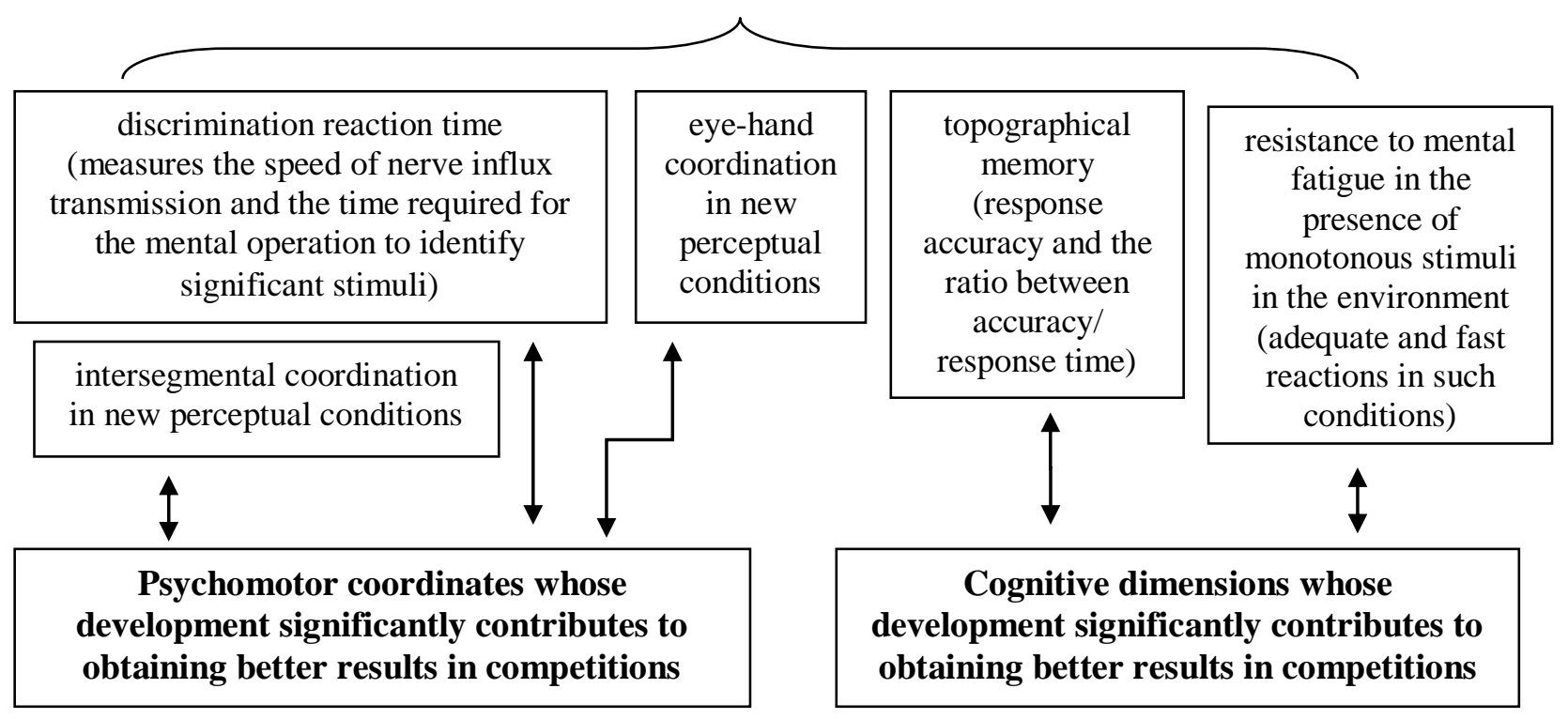

\section{JUNIOR TENNIS PLAYERS - BETWEEN 50-130 IN THE NATIONAL RANKING}

Figure 4. Psychomotor and cognitive model of performance junior tennis players (girls) 
The results of the study provided valuable information to specialists in the field of tennis, useful information in the training strategy (objective landmarks to be achieved in psychomotor and/or cognitive sphere), in order to scientifically steer sports training. In addition to coaches, the beneficiaries of the results are athletes - aspiring male and female tennis players on their way towards great performance (but also their parents), sports psychologists, sports clubs and, last but not least, the test producers. Coaches and sports psychologists, having at their disposal the psychomotor and cognitive models (the syntheticintegrative models presented above) of the top junior tennis players in Romania are able to maximise the effects of the training process, developing with priority the skills that make a difference. At the same time, the study can be the basis of the selection process of junior tennis players. Sports clubs (president, coach, managers, sponsors), as beneficiaries of research results, will be able to focus on (male or female) players, who have those psychomotor and cognitive skills that facilitate better sports performance. Through their performances nationally and later internationally, athletes are the country's image bearers. We also mention the producers of computerised or paper-and-pencil tests among the beneficiaries of the research data. They can focus their attention on creating tests that can educate, develop the psychomotor and intellectual dimensions of interest, which have a catalytic role on personal development and the ability to achieve sports performance.

The research conducted was limited by the psycho-physical condition (affectivemotivational factors, fatigue) of the participants at the time of testing. An unfavourable condition of junior tennis players at the time of testing may lead to variations in the quality of perceptual processes, variations in reaction time, alertness or the ability to process relevant information. Conversation and observation as research methods support the value of our study (athletes were observed during the test, the reporting of unfavourable condition leading to stopping the test). Another limitation of the study refers to the sample (the existence of a relatively small number of participants). Moreover, the situation could be different (the psychomotor and cognitive models developed could be different) if we investigate preadolescents or seniors. At the same time, it is necessary to approach other psychomotor and cognitive coordinates, for example - evaluation of speed and distance, assessment of the direction of movement, spatial orientation, static and dynamic balance, divergent thinking, etc. In order to complete the models made, from an informational point of view, a study of the personality system is very important - anxiety, aggression, risks taken, knowing that more anxious people take a higher stimulating risk, in other words, they act according to the principle of "all or nothing" (Makarowski et al., 2016a), but also that (physically, verbally, angry) aggressive people assume a low instrumental (calculated) risk (Makarowski et al., 2016b). Last but not least, it would be interesting to find out the psychomotor and cognitive model of tennis players ranked first in Europe and why not worldwide. All these aspects require new experimental investigations.

\section{References}

Aniței, M. (2007). Psihologie experimentală [Experimental psychology]. Credis.

Boksem, M. A., \& Tops, M. (2008). Mental fatigue: Costs and benefits. Brain Research Reviews, 59(1), 125-139. https://doi.org/10.1016/j.brainresrev.2008.07.001 
Castelnau, P., Albaret, J. M., Chaix, Y., \& Zanone, P. G. (2007). Developmental Coordination Disorder pertains to a deficit in perceptuo-motor synchronization independent of attentional capacities. Human Movement Science, 26(3), 477-490. https://doi.org/10.1016/j.humov.2007.03.001

Chen, Z. (2002). Analogical problem solving: A hierarchical analysis of procedural similarity. Journal of Experimental Psychology: Learning, Memory, and Cognition, 28(1), 81-98. https://doi.org/10.1037/0278-7393.28.1.81

Cojocariu, A., Ungurean, B. C., Oprean, A., \& Puni, A. R. (2019). The variability of visual choice reaction time to different colours in male non-athletes and qwan ki do elite athletes. Archives of Budo, 15, 303-309. http://archbudo.com/view/abstract/id/13044

Crespo, M., Reid, M., \& Quinn, A. (2006). Tennis psychology: Practical drills and the latest research. International Tennis Federation, ITF Ltd.

Davis, B., Bull, R., Roscoe, J., \& Roscoe, D. (2000). Physical education and the study of sport (4th ed.). Mosby Inc.

Erman, A., Şahan, A., \& Küçükkaya, A. (2013). The effect of one and two-handed backhand strokes on hand-eye coordination in tennis. Social and Behavioral Sciences, 93, 18001804. https://doi.org/10.1016/j.sbspro.2013.10.120

Furley, P., Bertrams, A., Englert, C., \& Delphia, A. (2013). Ego depletion, attentional control, and decision making in sport. Psychology of Sport and Exercise, 14(6), 900-904. https://doi.org/10.1016/j.psychsport.2013.08.006

Goethel, M. F., Ervilha, U. F., Sarmet Moreira, P. V., de Paula Silva, V., Bendillati, A. R., Cardozo, A. C., \& Gonçalves, M. (2019). Coordinative intra-segment indicators of karate performance. Archives of Budo, 15, 203-211. http://archbudo.com/view/abstract/id/12922

Gould, D., Medbery, R., Damarjian, N., \& Lauer, L. (1999). A survey of mental skills training knowledge, opinions, and practices of junior tennis coaches. Journal of Applied Sport Psychology, 11(1), 28-50. https://doi.org/10.1080/10413209908402949

Hsieh, T., Huang, C., \& Hung, T. (2010) Relationships between heart rate variability, attention, and athletic performance. International Journal of Sport and Exercise Psychology, 8(4), 473-475. https://doi.org/10.1080/1612197X.2010.9671964

Kaiser, M. L., Albaret, J. M., \& Doudin, P. A. (2009). Relationship between visual-motor integration, eye-hand coordination, and quality of handwriting. Journal of Occupational Therapy, Schools, \& Early Intervention, 2(2), 87-95. https://doi.org/10.1080/19411240903146228

Kantowitz, B. H., Roediger III, H. L., \& Elmes, D. G. (2015). Experimental psychology (10th ed.). Cengage Learning.

Lamoth, C. J. C., Daffertshofer, A., Huys, R. \& Beek, P. J. (2009). Steady and transient coordination structures of walking and running. Human Movement Science, 28(3), 371386. https://doi.org/10.1016/j.humov.2008.10.001

Levitt, S., \& Gutin, B. (1971). Multiple choice reaction time and movement time during physical exertion. Research Quarterly, 42(4), 405-410. https://doi.org/10.1080/10671188.1971.10615088

Grigore, V., Mitrache, G., \& Predoiu, R. (2016). Analogical transfer capacity and the discrimination reaction time in elite female tennis players. Romanian Journal of Experimental Applied Psychology, 7(Special Issue 1), 56-60. https://doi.org/10.15303/rjeap.2016.si1.a11

Liu, I., Levy, R. M., Bartonc, J. S., \& Iaria, G. (2011). Age and gender differences in various topographical orientation strategies. Brain Research, 1410, 112-119.

https://doi.org/10.1016/j.brainres.2011.07.005 
Makarowski, R., Makarowski, P., \& Kamiński, Z. (2016a). Adrenaline instead of amphetamine - replacing psychoactive substances with parachute jumps. The Journal of General Psychology, 143(4), 281-297. http://dx.doi.org/10.1080/00221309.2016.1214101

Makarowski, R., Makarowski, P., Smolicz, T., \& Plopa, M. (2016b). Risk profiling of airline pilots: Experience, temperamental traits and aggression. Journal of Air Transport Management, 57, 298-305. http://dx.doi.org/10.1016/j.jairtraman.2016.08.013

Nikkhah-Farkhani, Z., \& Piotrowski, A. (2020). Nurses' turnover intention: A comparative study between Iran and Poland. Medycyna Pracy, 71(4), 413- 420. https://doi.org/10.13075/mp.5893.00950

O’Sullivan, S. B., Schmitz, T. J., \& Fulk, G. (2014). Physical rehabilitation (6th ed.). F. A. Davis Company.

Pearson, D. G., Ball, K., \& Smith, D. T. (2014). Oculomotor preparation as a rehearsal mechanism in spatial working memory. Cognition, 132(3), 416-428. https://doi.org/10.1016/j.cognition.2014.05.006

Piotrowski, A. (2018). Self-evaluation of personal physical health, accidents while performing duty and preventive treatment of stress in Prison Service. Medycyna Pracy, 69(4), 425-438. https://doi.org/10.13075/mp.5893.00535

Piotrowski, A., Szulc, M., Boe, O., Marineanu, V., Rawat, S., \& Deshpande, A. (2020). Threat of using alcohol and psychoactive substances in uniformed formations. Miscellanea Anthropologica et Sociologica, 21(1), 107-125. https://czasopisma.bg.ug.edu.pl/index.php/maes/article/view/4514

Predoiu, A. (2020). Metodologia cercetării științifice. Aplicații practice și elemente de statistică neparametrică [Scientific research methodology. Practical applications and elements of nonparametric statistics]. Discobolul.

Predoiu, A., Predoiu, R., Grigore, V., \& Mitrache, G. (2017). Analogical reasoning, mobility of attention and their link with PSI in junior handball teams. Discobolul - Physical Education, Sport and Kinetotherapy Journal, 50(4), 5-10. https://discobolulunefs.ro/wpcontent/uploads/2018/10/Discobolul-Nr.-50-decembrie-2017.pdf

Predoiu, R. (2016). Psihologia sportului. Maximizarea performanței sportive [Sport psychology. Maximisation of sport performance]. Polirom.

Schumway-Cook, A., \& Woollacott, M. H. (2012). Motor control: Translating research into clinical practice $\left(4^{\text {th }}\right.$ ed.). Lippincott Williams \& Wilkins.

Stănescu, R. (2014a). Resurse pentru creșterea capacității de performanță în tenis [Resources for increasing the performance capacity in tennis]. Bren.

Stănescu, R. (2014b). Mental training assisted by neurofeedback - as a method to improve technical level in tennis. Proceedings of the 10th International Scientific Conference ELSE - eLearning and Software for Education, 4, 217-222. DOI: 10.12753/2066-026X-14-262

Sternberg, R. (1977). Component process in analogical reasoning. Psychological Review, 84(4), 353-378. https://doi.org/10.1037/0033-295X.84.4.353

Tüdös, Ş. (2000). Criterii psihologice în fundamentarea și structurarea pregătirii sportive [Psychological criteria in substantiating and structuring sports training]. Paideia.

Tüdös, Ş., Predoiu, R., \& Predoiu, A. (2015). Topographical memory and the concentration of attention in top female tennis players. Social and Behavioral Sciences, 190, 293-298. https://doi.org/10.1016/j.sbspro.2015.05.001

Zory, R., Vuillerme, N., Pellegrini, B., Schena, F., \& Rouard, A. (2009). Effect of fatigue on double pole kinematics in sprint cross-country skiing. Human Movement Science, 28(1), 85-98. DOI: 10.1016/j.humov.2008.05.002 